\title{
Outcomes of Tongue Base Reduction and Lingual Tonsillectomy for Residual Pediatric Obstructive Sleep Apnea after Adenotonsillectomy
}

\author{
Seckin Ulualp ${ }^{10}$ \\ ${ }^{1}$ Department of Otolaryngology, University of Texas Southwestern \\ Medical Center at Dallas, Dallas, Texas, United States \\ Int Arch Otorhinolaryngol 2019;23:e415-e421.
}

\author{
Address for correspondence Seckin Ulualp, MD, Department of \\ Otolaryngology, University of Texas Southwestern Medical Center at \\ Dallas, 5323 Harry Hines Blvd, Dallas, TX 75390, United States \\ (e-mail: seckin.ulualp@utsouthwestern.edu).
}

\begin{abstract}
Introduction Upper airway obstruction at multiple sites, including the velum, the oropharynx, the tongue base, the lingual tonsils, or the supraglottis, has been resulting in residual obstructive sleep apnea (OSA) after tonsillectomy and adenoidectomy (TA). The role of combined lingual tonsillectomy and tongue base volume reduction for treatment of OSA has not been studied in nonsyndromic children with residual OSA after TA.

Objective To evaluate the outcomes of tongue base volume reduction and lingual tonsillectomy in children with residual OSA after TA.

Methods A retrospective chart review was conducted to obtain information on history and physical examination, past medical history, findings of drug-induced sleep endoscopy (DISE), of polysomnography (PSG), and surgical management. Pre- and postoperative PSGs were evaluated to assess the resolution of OSA and to determine the improvement in the obstructive apnea-hypopnea index (oAHI) before and after the surgery.

Results A total of 10 children ( 5 male, 5 female, age range: $10-17$ years old, mean age: $14.5 \pm 2.6$ years old) underwent tongue base reduction and lingual tonsillectomy. Drug-induced sleep endoscopy (DISE) revealed airway obstruction due to posterior displacement of the tongue and to the hypertrophy of the lingual tonsils. All of the patients reported subjective improvement in the OSA symptoms. All of the patients had improvement in the oAHI. The postoperative oAHI was lower than the preoperative $\mathrm{oAHI}(p<0.002)$. The postoperative apnea-hypopnea index during rapid eye movement sleep (REM-AHI) was lower than the preoperative REM-AHI $(p=0.004)$. Obstruc-

Keywords

- tonsillectomy

- glossectomy

- sleep apnea

- obstructive

- child tive sleep apnea was resolved in children with normal weight. Overweight and obese children had residual OSA. Nonsyndromic children had resolution of OSA or mild OSA after the surgery.

Conclusions Tongue base reduction and lingual tonsillectomy resulted in subjective and objective improvement of OSA in children with airway obstruction due to posterior displacement of the tongue and to hypertrophy of the lingual tonsils.
\end{abstract}

received

July 15, 2018

accepted

February 17, 2019
DOI https://doi.org/

10.1055/s-0039-1685156. ISSN 1809-9777.
Copyright $\odot 2019$ by Thieme Revinter

Publicações Ltda, Rio de Janeiro, Brazil
License terms

(ㄷ) (i) $\ominus$ (\$) 


\section{Introduction}

Upper airway obstruction in children with obstructive sleep apnea (OSA) has been documented at single or multiple sites. ${ }^{1}$ Drug-induced sleep endoscopy (DISE) performed at the time of tonsillectomy and adenoidectomy (TA) has revealed that the majority of children with OSA had multiple sites of airway obstruction. ${ }^{1}$ Upper airway obstruction (UAO) at multiple sites, including the velum, the oropharynx, the tongue base, the lingual tonsils, or the supraglottis, has been resulting in residual OSA after TA. ${ }^{2-4}$ The outcomes of surgical management of residual OSA after TA have been increasingly reported.

Hypertrophy of the lingual tonsils has been implicated in the pathogenesis of residual OSA in healthy children, in children with Down syndrome, and in obese children. ${ }^{5-8}$ Macroglossia and glossoptosis have been associated with OSA in children with Down syndrome. The polysomnography (PSG) parameters improved in children with OSA who had undergone lingual tonsillectomy or partial glossectomy as a standalone procedure. ${ }^{2,4,7-9}$ Concurrent lingual tonsillectomy and midline posterior glossectomy alleviated OSA in adults and in children with Down syndrome. ${ }^{10,11}$ The role of combined lingual tonsillectomy and tongue base volume reduction for the treatment of OSA has not been studied in nonsyndromic children with residual OSA after TA. The aim of the present study is to evaluate the outcomes of tongue base volume reduction and lingual tonsillectomy in children with residual OSA after TA.

\section{Materials and Methods}

The charts of patients who had undergone tongue base volume reduction and lingual tonsillectomy for treatment of residual OSA after TA between September 2008 and February 2016 were reviewed retrospectively. The present study was approved by the Institutional Human Research Review Board (STU 022016-086). An electronic medical record system documenting surgeries performed by the author was used to identify the patients who had undergone tongue base volume reduction and lingual tonsillectomy for the treatment of residual OSA after TA. The indications for tongue base volume reduction and lingual tonsillectomy were residual OSA after TA, lingual tonsil hypertrophy displacing the epiglottis posteriorly, and anterior-posterior movement of the tongue obstructing the view of the glottis during DISE. Patients $<18$ years old were included in the study if residual OSA was documented by PSG. Patients were not excluded due to craniofacial anomalies, developmental delay, neuromuscular disorders, or other chronic conditions.

All of the patients presented to the pediatric otolaryngology clinic for treatment of PSG-proven residual OSA after TA. Drug-induced sleep endoscopy was recommended to evaluate the location of the upper airway obstruction. Druginduced sleep endoscopy was performed using the previously described protocol. ${ }^{1}$ After the patients underwent DISE, the risks, benefits, and alternatives to tongue base reduction and lingual tonsillectomy were discussed at a clinic visit. The lingual tonsil hypertrophy was divided into 4 groups: grade 1 (none to minimal hypertrophy), grade 2 (mild, $<50 \%$ filling of the vallecula), grade 3 (moderate, $>50 \%$ effacement of the vallecula), and grade 4 (severe, unable to visualize the epiglottis). ${ }^{12}$ The lingual tonsils were removed if they displaced the epiglottis posteriorly. The diagnosis of posterior displacement of the tongue was made when the tongue showed an anterior-posterior movement that caused intermittent airway obstruction and obstructed the view of the glottis. ${ }^{1,13}$

Lingual tonsillectomy and tongue base reduction was performed as follows: after inducing general anesthesia, the patient was nasotracheally intubated and a tooth guard was placed. An age-appropriate Benjamin or Parsons laryngoscope (Karl Storz, El Segundo, California, USA) was used to provide visualization of the vallecula, of the epiglottis, and of the lingual tonsils. The laryngoscope was placed in suspension with the aid of a self-retaining laryngoscope holder (Karl Storz, El Segundo, California, USA) secured to a Mayo stand (Pedigo, Vancouver, Washington, USA). Plasma-mediated bipolar radiofrequency, that is, coblation, was used to remove the lingual tonsils. The coblator (Smith \& Nephew, Austin, Texas, USA) settings were 7 for ablation and 3 for coagulation. The procedure was performed under endoscopic guidance using a video screen. The laryngoscope (Karl Storz, El Segundo, California, USA) was repositioned to ensure the adequate removal of the right, middle, and left lingual tonsil regions. The lingual tonsils were removed until the vallecula and epiglottis were exposed. The laryngoscope was removed to prepare for tongue base volume reduction.

Tongue base volume reduction was performed using the submucosal minimally invasive lingual excision (SMILE) technique. ${ }^{14}$ Jennings mouth retractor (SkylarCorp, West Chester, Pennsylvania, USA) was placed to keep the mouth open. The paths of the lingual arteries were identified by using a handheld Doppler device (Koven Technology, St. Louis, Missouri, USA). The coblator wand was introduced through the incision made $1 \mathrm{~cm}$ anterior to the circumvallate papillae in the midline of the tongue. The wand was moved in a superior to inferior fashion to remove the tongue tissue toward the vallecula. Tissue removal was guided by palpation and by introducing a $1.9 \mathrm{~mm}$ telescope (Karl Storz, El Segundo, California, USA) into the surgical cavity to visualize the surgical field at the base of the tongue. The lateral extent of the dissection was limited to the lateral edges of the epiglottis. The posterior extent of the dissection was limited to an imaginary line drawn vertically from the level of the hyoepiglottic ligament. The inferior extent of the dissection was of between 1 and $2 \mathrm{~cm}$ from the surface of the tongue. The incision was closed. The patients were extubated and monitored for $<24$ hours. The patients were discharged home with 5 days of clindamycin after a good oral intake and pain control was achieved. Pain management was accomplished with the use of an alternating regimen of acetaminophen and ibuprofen. ${ }^{15}$

All of the patients underwent an all-night, attended PSG in the same sleep laboratory at a tertiary care children hospital before and after the surgery. Sleep measurements were 
performed in accordance with the guidelines published by the American Academy of Sleep Medicine. Pediatric sleep medicine specialists scored the PSG. The obstructive apneahypopnea index (oAHI) was calculated as the sum of obstructive apneas and hypopneas per hour. In children $<13$ years old, the severity of OSA was categorized according to the oAHI: mild, oAHI between 2 and 5; moderate, oAHI between 5 and 10 ; or severe, oAHI $>10 .^{1}$ In children $>13$ years old, the severity of OSA was categorized according to the oAHI: mild, oAHI between 5 and 15; moderate, oAHI between 15 and 30; or severe, oAHI $>30 .{ }^{11,16,17}$ The pre- and postoperative age category was the same in all of the patients. The apnea-hypopnea index during rapid eye movement sleep (REM-AHI) was calculated as the sum of obstructive apnea, obstructive hypopnea, mixed apneas, and central apneas occurring per hour during REM sleep.

Data pertaining to age, gender, past medical history, comorbid conditions, body mass index (BMI), and findings of the PSG were obtained from the charts. Children with a BMI $>$ the 95th percentile were considered as obese. The group of nonobese children was further divided into 3 subgroups; overweight $\left(85^{\text {th }}<\right.$ BMI $<95^{\text {th }}$ percentile), normal weight $\left(5^{\text {th }}<\mathrm{BMI}<85^{\text {th }}\right.$ percentile), and underweight (BMI $<5^{\text {th }}$ percentile).

The pre- and postoperative oAHI, REM-AHI, and minimum saturation of peripheral oxygen $\left(\mathrm{min} \mathrm{spO}_{2}\right)$ were compared using a nonparametric test (Wilcoxon signed rank test). The percentage decrease in the oAHI and the percentage decrease in the REM-AHI in the studied weight categories were compared using a parametric test (one-way analysis of variance [ANOVA]). The percentage decrease in the oAHI and the percentage decrease in the REM-AHI between children without Down syndrome and children with Down syndrome were compared using a parametric test (paired ttest). Parametric tests (one way ANOVA and paired t-test) were used for data passing the Shapiro-Wilk test for normality, and a nonparametric test (Wilcoxon signed rank test) was used for data failing the Shapiro-Wilk test for normality. A pvalue of $<0.05$ was considered significant. Data are presented as mean \pm standard error (SE).

\section{Results}

A total of 10 children ( 5 male, 5 female; age range: 10 to 17 years old; mean age: $14.5 \pm 2.6$ years old) underwent tongue base reduction and lingual tonsillectomy with no complications (-Table 1). Comorbid conditions included Down syndrome in 5 patients, attention deficit hyperactivity disorder in 2 patients, and asthma in 1 patient. The children did not have retrognathia or micrognathia. The children with Down syndrome had macroglossia. The majority of patients

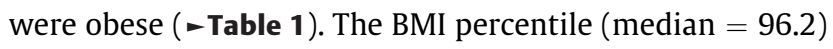
and the $z$-scores (median $=1.79$ ) of the patients at the time of the preoperative PSG were similar to those of the postoperative PSG (median $=96.3$, median $=1.80$, respectively). The DISE revealed additional sites of airway obstruction: anterior-posterior obstruction at the level of the soft palate in one patient, and concentric obstruction at the level of the oropharynx in two patients. The patient with anterior-posterior obstruction at the level of the soft palate had no residual OSA. Of the two patients with concentric obstruction at the level of the oropharynx, one had residual OSA. The majority of patients had grade II lingual tonsil hypertrophy (-Table 1). The patients had multiple OSA symptoms ( - Table 1). All of the patients reported subjective improvement in the loudness and in the frequency of snoring and resolution of pauses in breathing, gasping for air, mouth breathing, day time somnolence, sleepwalking, sleep talking, teeth grinding, enuresis, and feeling tired after the surgery.

The severity of the OSA was mild in two patients, moderate in two patients, and severe in six patients. The interval between the surgery and the postoperative PSG was of 2 months in 5 patients, 3 months in 2 patients, 4 months in 1 one patient, and 5 months in 2 patients. The patients with mild OSA had no OSA after the surgery. The patients with moderate OSA had mild OSA after the surgery. Out of the six patients with severe OSA, two patients had resolution of the OSA, two patients had mild OSA, two patients had moderate OSA, and two patients had severe OSA. All of the patients presented a reduction in the OAHI and in the REM-AHI. The percentage decrease in the oAHI ( $52 \pm 9.5 \%$, range: $10-98 \%)$ was not significantly different than the percentage decrease in the REM-AHI (48 $\pm 9.6 \%$, range: $30-87 \%)(p=0.3)$.

The postoperative oAHI (median $=5.3$; range: $1.7-16.6)$ was lower than the preoperative oAHI (median $=26.3$; range: $6.3-73.9)(p<0.002)$ (-Table 2). The postoperative REM-AHI (median $=15.8$; range: $0-41$ ) was lower than the preoperative REM-AHI (median $=27.2$; range: $0-65$ ) $(p=0.004)$. The postoperative $\min \mathrm{spO}_{2}$ was not significantly different than the preoperative $\min \mathrm{spO}_{2}(p=0.4)$.

Two patients with normal weight had severe OSA prior to the surgery. In patients with normal weight, the OSA was resolved after the surgery. Two overweight patients had mild OSA and severe OSA before the surgery. Mild OSA was resolved after the surgery in an overweight patient. One overweight patient with severe OSA continued to have severe OSA after the surgery. The severity of the OSA in obese patients was mild in 1 patient, moderate in 2 patients, and severe in 3 patients before the surgery. One obese patient with mild OSA had no OSA after the surgery. Obese patients with moderate OSA had mild OSA after the surgery. Of the three obese patients with severe OSA, two patients had mild OSA and 1 patient had severe OSA after the surgery. The percentage decrease in the oAHI $(96 \pm 2.8 \%)$ in children who had normal weight was higher than the percentage decrease in the oAHI in children who were overweight $(36 \pm 26.1 \%)$ or obese $(29 \pm 16.5 \%)(p=0.03)$. In children who had normal weight, the percentage decrease in the REM-AHI $(86 \pm 0.7 \%)$ was higher than the percentage decrease in the oAHI in children who were overweight $(34 \pm 5.6 \%)$ or obese $(18 \pm 20.8 \%)(p=0.01)$.

In the patients with Down syndrome, the severity of OSA was mild in one patient, moderate in one patient, and severe in three patients prior to the surgery. Mild OSA was resolved after the surgery in the child with Down syndrome. The child with Down syndrome and moderate OSA had mild OSA after the surgery. In children with Down syndrome and severe 
Table 1 Demographics, severity of pre- and postoperative obstructive sleep apnea and grade of lingual tonsil hypertrophy

\begin{tabular}{|c|c|c|c|c|c|c|c|c|}
\hline Patient & Age & Gender & $\begin{array}{l}\text { Weight } \\
\text { (BMI\%/z-score) }\end{array}$ & $\begin{array}{l}\text { Down } \\
\text { syndrome }\end{array}$ & $\begin{array}{l}\text { OSA severity } \\
\text { (oAHI/REM-AHI) }\end{array}$ & $\begin{array}{l}\text { Lingual tonsil } \\
\text { hypertrophy }\end{array}$ & $\begin{array}{l}\text { Preoperative } \\
\text { dymptoms }\end{array}$ & $\begin{array}{l}\text { Residual } \\
\text { OSA } \\
\text { (oAHI/ } \\
\text { REM-AHI) }\end{array}$ \\
\hline 1 & 10 & $\bar{F}$ & $\begin{array}{l}\text { Obese } \\
(99.8 / 2.95)\end{array}$ & No & $\begin{array}{l}\text { Moderate } \\
(6.3 / 21.6)\end{array}$ & II & $\begin{array}{l}\text { Snoring, } \\
\text { mouth breath- } \\
\text { ing, sleepwalk- } \\
\text { ing, sleep } \\
\text { talking, teeth } \\
\text { grinding, } \\
\text { enuresis }\end{array}$ & $\begin{array}{l}\text { Yes } \\
(5.7 / 18.6)\end{array}$ \\
\hline 2 & 17 & $\mathrm{~F}$ & $\begin{array}{l}\text { Normal } \\
(38.0 / 0.93)\end{array}$ & Yes & $\begin{array}{l}\text { Severe } \\
(33.2 / 18.6)\end{array}$ & III & $\begin{array}{l}\text { Snoring, } \\
\text { pauses in } \\
\text { breathing, } \\
\text { mouth breath- } \\
\text { ing, daytime } \\
\text { somnolence }\end{array}$ & $\begin{array}{l}\text { No } \\
(1.9 / 5.8)\end{array}$ \\
\hline 3 & 15 & $\mathrm{~F}$ & $\begin{array}{l}\text { Normal } \\
(50.7 / 0.12)\end{array}$ & No & $\begin{array}{l}\text { Severe } \\
(73.9 / 8.0)\end{array}$ & III & $\begin{array}{l}\text { Snoring, } \\
\text { gasping for air, } \\
\text { pauses in } \\
\text { breathing, } \\
\text { waking up } \\
\text { tired, daytime } \\
\text { somnolence }\end{array}$ & $\begin{array}{l}\text { No } \\
(1.7 / 1.1)\end{array}$ \\
\hline 4 & 17 & $\mathrm{M}$ & $\begin{array}{l}\text { Overweight } \\
(86.9 / 1.12)\end{array}$ & No & $\begin{array}{l}\text { Mild } \\
(11.0 / 27.7)\end{array}$ & III & $\begin{array}{l}\text { Snoring, } \\
\text { daytime } \\
\text { somnolence, } \\
\text { mouth } \\
\text { breathing }\end{array}$ & $\begin{array}{l}\text { No } \\
(4.9 / 17.1)\end{array}$ \\
\hline 5 & 13 & $\mathrm{M}$ & $\begin{array}{l}\text { Obese } \\
(95.4 / 1.69)\end{array}$ & Yes & $\begin{array}{l}\text { Severe } \\
(26.1 / 0)\end{array}$ & II & $\begin{array}{l}\text { Snoring, } \\
\text { pauses in } \\
\text { breathing, } \\
\text { daytime } \\
\text { somnolence }\end{array}$ & $\begin{array}{l}\text { Yes } \\
(15.6 / 0)\end{array}$ \\
\hline 6 & 16 & $\mathrm{M}$ & $\begin{array}{l}\text { Obese } \\
(97.6 / 1.99)\end{array}$ & Yes & $\begin{array}{l}\text { Moderate } \\
(26.5 / 37.4)\end{array}$ & II & $\begin{array}{l}\text { Pauses in } \\
\text { breathing, } \\
\text { mouth } \\
\text { breathing }\end{array}$ & $\begin{array}{l}\text { Yes } \\
(16.6 / 2.9)\end{array}$ \\
\hline 7 & 17 & $\mathrm{M}$ & $\begin{array}{l}\text { Overweight } \\
(93.4 / 1.55)\end{array}$ & Yes & $\begin{array}{l}\text { Severe } \\
(42.7 / 58.6)\end{array}$ & II & $\begin{array}{l}\text { Snoring, } \\
\text { daytime } \\
\text { somnolence }\end{array}$ & $\begin{array}{l}\text { Yes } \\
(15.1 / 4.1)\end{array}$ \\
\hline 8 & 14 & $\mathrm{M}$ & $\begin{array}{l}\text { Obese } \\
(99.0 / 2.6)\end{array}$ & No & $\begin{array}{l}\text { Severe } \\
(60.9 / 65)\end{array}$ & II & $\begin{array}{l}\text { Snoring, } \\
\text { pauses in } \\
\text { breathing } \\
\text { mouth breath- } \\
\text { ing, daytime } \\
\text { somnolence, } \\
\text { feeling tired }\end{array}$ & $\begin{array}{l}\text { Yes } \\
(15.5 / \\
21.5)\end{array}$ \\
\hline 9 & 11 & $\mathrm{~F}$ & $\begin{array}{l}\text { Obese } \\
(97 / 1.9)\end{array}$ & No & $\begin{array}{l}\text { Severe } \\
(10.1 / 17.5)\end{array}$ & II & $\begin{array}{l}\text { Snoring, } \\
\text { feeling tired, } \\
\text { daytime } \\
\text { somnolence }\end{array}$ & $\begin{array}{l}\text { Yes } \\
(3.7 / 2.2)\end{array}$ \\
\hline 10 & 14 & $\mathrm{~F}$ & $\begin{array}{l}\text { Obese } \\
(97.3 / 1.93)\end{array}$ & Yes & $\begin{array}{l}\text { Mild } \\
(7.4 / 26.8)\end{array}$ & II & $\begin{array}{l}\text { Snoring, } \\
\text { gasping for air, } \\
\text { mouth } \\
\text { breathing }\end{array}$ & $\begin{array}{l}\text { No } \\
(3.2 / 14.5)\end{array}$ \\
\hline
\end{tabular}

Abbreviations: BMI\%, body mass index percentile; F, female; M, male; oAHI, obstructive apnea-hypopnea index; OSA, Obstructive sleep apnea; REM$\mathrm{AHI}$, apnea-hypopnea index during rapid eye movement sleep. 
Table 2 Comparison of polysomnography parameters in the entire group, in nonsyndromic patients, and in patients with Down syndrome

\begin{tabular}{|c|l|l|l|}
\hline & Entire group & $\begin{array}{l}\text { Non- } \\
\text { syndromic }\end{array}$ & $\begin{array}{l}\text { Down } \\
\text { syndrome }\end{array}$ \\
\hline $\begin{array}{l}\text { Obstructive AHI } \\
\text { median (mean } \pm \text { SE) }\end{array}$ & & & \\
\hline Preoperative & $\begin{array}{l}26.3^{*} \\
(30 \pm 7.3)\end{array}$ & $\begin{array}{l}11^{*} \\
(32 \pm 14.4)\end{array}$ & $\begin{array}{l}26.5^{*} \\
(27 \pm 5.7)\end{array}$ \\
\hline Postoperative & 5.3 & 5 & 15.1 \\
$(8 \pm 2.0)$ & $(6 \pm 2.3)$ & $(10 \pm 3.2)$ \\
\hline $\begin{array}{l}\text { REM-AHI } \\
\text { median (mean } \pm \text { SE) }\end{array}$ & & & \\
\hline Preoperative & $27.2^{*}$ & $21.6^{*}$ & $32.1^{*}$ \\
$(31 \pm 6.6)$ & $(28 \pm 9.7)$ & $(33 \pm 8.1)$ \\
\hline Postoperative & 15.8 & 17.1 & 14.5 \\
$(14 \pm 4.0)$ & $(12 \pm 4.3)$ & $16 \pm 5.8$ \\
\hline $\begin{array}{l}\text { Min SpO2 } \\
\text { median (mean } \pm \text { SE) }\end{array}$ & & & \\
\hline Preoperative & 91 & 90 & 92 \\
& $(91.4 \pm 1.2)$ & $(90.8 \pm 1.6)$ & $(91.2 \pm 1.2)$ \\
\hline Postoperative & 92.5 & 90 & 93 \\
& $(91.9 \pm 1.1)$ & $(91.6 \pm 2.3)$ & $(93.0 \pm 1.6)$ \\
\hline
\end{tabular}

Abbreviations: $\mathrm{AHI}$, apnea hypopnea index; min $\mathrm{SpO} 2$, minimum saturation of peripheral oxygen; REM, rapid eye movement; SE, standard error. ${ }^{*}=p<0.05$.

OSA, the OSA was resolved in one patient and persisted in two patients. The postoperative oAHI (median $=15.1$; range: 1.9-16.6) was lower than the preoperative oAHI (median $=26.5$; range: $7.4-42.7)(p=0.03)$. The postoperative REM-AHI (median $=14.5$; range: $0-41$ ) was lower than the preoperative REM-AHI (median $=32.1$; range: $0-58.6$ ) $(p=0.02)$.

In the patients without Down syndrome, the severity of OSA was mild in one patient, moderate in one patient, and severe in three patients prior to the surgery. Mild OSA was resolved after the surgery in the child without Down syndrome. The children with no Down syndrome and moderate OSA had mild OSA after the surgery. In the children with no Down syndrome and severe OSA, OSA was resolved in two patients and persisted in one patient. The postoperative oAHI (median $=5$; range: $1.7-15.5$ ) was lower than the preoperative oAHI (median $=11$; range: $6.3-73.9)(p=0.04)$. The postoperative REM-AHI (median $=17.1$; range: $1.1-21.5$ ) was lower than the preoperative REM-AHI (median $=21.6$; range: $8-65)(p=0.04)$.

The percentage decrease in the oAHI $(40 \pm 9.4 \%)$ and in the REM-AHI (48 $\pm 14.6 \%)$ in the children with Down syndrome was not significantly different than the percentage decrease in the oAHI $(60 \pm 14.4 \%)$ and in the REM-AHI $(55 \pm 14.0 \%)$ in the children without Down syndrome $(p=0.2)$.

\section{Discussion}

The development of new operative techniques and the multisite airway surgery to alleviate obstruction in children with OSA have been increasingly reported since the identification of the upper airway obstruction improved. ${ }^{4,5,7-9,11,14,18}$ In the present study, tongue base volume reduction and lingual tonsillectomy were performed to address the obstruction at the level of the retrolingual airway in children who had residual OSA after TA.

The obstruction at the level of the retrolingual airway, that is, the region of the pharynx posterior to the vertical portion of the tongue, has been suggested to cause OSA. Procedures reducing the volume of the tongue have enhanced the retrolingual airway flow. Lingual tonsillectomy has been used to improve the retrolingual airway patency by removing the obstructing lingual tonsil tissue. Decreasing the tongue tissue volume and removing the lingual tonsils as well as the resultant scar has reduced the collapsibility of the tongue base. ${ }^{14}$ The effect of combined tongue base volume reduction and lingual tonsillectomy on PSG parameters and on OSA symptoms in nonsyndromic children has not been reported.

In the present study, the concurrent use of tongue base volume reduction and lingual tonsillectomy resulted in resolution of OSA in 4 of the 10 children with OSA. A total of 8 out of the 10 children had improvement in OSA symptoms and a decrease in the oAHI at the postoperative PSG. While children with normal weight had resolution of the OSA symptoms and normalization of the oAHI, children who were overweight or obese had resolution of the OSA symptoms and improvement in the oAHI. The factors contributing to residual OSA per PSG findings in the present study can be attributed to variables inherent to the characteristics of the patient, to suboptimal assessment of upper airway obstruction, to upper airway muscle hypotonia, to retropalatal obstruction, to untreated sites of UAO, or to an inadequate amount of reduction in the tongue tissue volume.

Obesity has been a well-known risk factor for residual OSA after TA. The prevalence of residual OSA after TA in obese children ranged from 45 to $76 \%{ }^{19-21}$ Obesity has been shown to contribute to residual OSA after TA via multiple factors, such as deposition of adipose tissue around the pharynx and the neck, ${ }^{22-24}$ cytokine overproduction, ${ }^{25,26}$ exacerbation of the burden on the upper airway, and weakening of compensatory neuromuscular responses. ${ }^{25}$ In the present study, since the normalization of the oAHI after lingual tonsillectomy and tongue base volume reduction did not occur in children who were obese or overweight, weight appears to be a factor contributing to residual OSA after lingual tonsillectomy and tongue base volume reduction. The effect of weight on the prevalence of residual OSA after lingual tonsillectomy and tongue base volume reduction in children merits further investigation in a larger number of children.

Children with Down syndrome have been more likely to have residual OSA after TA, possibly due to macroglossia, glossoptosis, midface hypoplasia, hypopharyngeal collapse, and lingual tonsil hypertrophy. In the present study, 2 out of the 5 children with Down syndrome had resolution of OSA per PSG findings after tongue base volume reduction and lingual tonsillectomy. Resolution of OSA per PSG findings was documented in 3 of the 5 nonsyndromic children. Nonetheless, the oAHI decreased in all of the children with Down syndrome, as well as in nonsyndromic children. 
Accurate and reliable identification of UAO has been critical to improve the outcomes of surgery for OSA in children. To date, a gold standard method to assess UAO in children with OSA has not been established. Cine magnetic resonance imaging (MRI) and DISE have been used to evaluate UAO during pharmacologically produced unconscious sedation-simulating sleep. Although cine MRI has not been broadly used, previous studies have documented recurrent adenoid tissue, glossoptosis, soft palate collapse, hypopharyngeal collapse, and enlarged lingual tonsils as sites of obstruction in children with residual OSA after TA. ${ }^{13,27,28}$ Drug-induced sleep endoscopy has revealed multiple sites of obstruction, including a combination of the velum, of the oropharynx, of the tongue base, of the lingual tonsils, and of the supraglottis in children with residual OSA after TA. ${ }^{2-4}$ The comparison of the findings of cine MRI and DISE showed similar sites of UAO in the majority of children with residual OSA after TA. ${ }^{28}$ The outcomes of cine MRI-directed surgery have not been reported in children with residual OSA after TA; however, DISE-directed surgery improved the outcomes of sleep surgery in children with residual OSA after TA. 2,4,18

In the present study, DISE was used to localize the site of UAO. Drug-induced sleep endoscopy has been increasingly used to evaluate UAO in children with OSA; however, analysis of the multi-institutional practice patterns for pediatric DISE has revealed lack of consensus on the patient selection criteria, on the anesthetic protocol, on the timing of DISE, and on a standardized scoring method. ${ }^{29}$ Variations in DISE practice patterns have potential to result in inter-institutional discrepancies in the findings of UAO and in the outcomes of DISEdirected surgery. Identification of optimum methods to diagnose sites of UAO may aid the development of surgical techniques and the improvement of surgical outcomes in children with OSA.

Conceivably, inadequate reduction of tongue tissue volume may result in residual OSA after SMILE. Glossectomy techniques, such as external submucosal glossectomy, percutaneous submucosal glossectomy, SMILE, intraoral submucosal midline glossectomy, and intraoral submucosal lingualplasty have been used for tongue base surgery. Patient selection criteria to choose the surgical procedure for tongue base volume reduction and the volume of tongue tissue to be removed for treatment of OSA in children are yet to be defined. In the present study, the SMILE technique was used due to its low morbidity and low risk for compromising tongue function. The amount of tissue removed from the tongue was not quantified; therefore, a possible association between the volume of lingual tonsil and tongue tissue and improvement in the PSG parameters could not be assessed in the present study.

In the present study, the patients did not have a history of high arched palate or of restricted lingual frenulum. The lingual frenulum length was not measured in the present study; however, short lingual frenulum has been implicated in the pathogenesis of OSA in children. ${ }^{30}$ The role of myofunctional therapy in the management of OSA in adults and in children with OSA has been increasingly studied. ${ }^{31-34}$ Active and passive myofunctional therapy involves isotonic and isometric exercises in order to strengthen the oral cavity and the oropharyngeal structures. A meta-analysis of myofunctional therapy outcomes in children revealed complete remission of OSA in 60\% of the children who complied with the treatment. The role of myofunctional therapy, restricted lingual frenulum, and high arched palate in the management of residual OSA after TA merits further systematic investigations in larger groups of nonsyndromic children.

The present study is the first to evaluate the outcomes of combined tongue base reduction and lingual tonsillectomy on the PSG parameters and on OSA symptoms in nonsyndromic children with residual OSA after TA. The results of the present study are limited on several fronts. The first limitation is the small number of patients. A small number of patients may lead to false negative results. The retrospective nature of the study and the small number of patients restricted the assessment of the effects of the diversities in demographics, weight, and severity of OSA. A further limitation is the lack of information on the quality of life. All of the caregivers reported resolution of OSA symptoms; however, normalization of PSG criteria was not present in all of the patients. A systematic assessment of objective and subjective outcomes has potential to better define the effectiveness of combined tongue base volume reduction and lingual tonsillectomy. Postoperative PSG testing was conducted between 2 and 5 months after the surgery. The long-term outcomes of combined tongue base reduction and lingual tonsillectomy need to be determined. Internal validity, external validity, and ecological validity of scientific studies have been of concern to researchers. The present study was not immune to the effects of following the study protocol on external validity. Clinical study designs with well-defined inclusion and exclusion criteria enhance the internal validity; however, these measures limit the external validity, that is, generalizability across the studied conditions and generalizability across patients. In the present study, higher internal validity was achieved by providing detailed description of surgical indications, comorbidities, obesity status, and including nonsyndromic children and children with Down syndrome. The extent to which the present study findings can be generalized from the children with Down syndrome to children with other syndromes or other comorbidities is limited.

From a clinical perspective, the findings of the present study demonstrate that combined tongue base volume reduction and lingual tonsillectomy result in improvement in symptoms and in PSG parameters in nonsyndromic children, as well as in children with Down syndrome after TA. Clinicians should be cognizant of the lack of normalization of PSG parameters in some children after combined tongue base volume reduction and lingual tonsillectomy and counsel caregivers prior to surgery. The PSG should be repeated after the surgery due to risk of residual OSA after combined tongue base volume reduction and lingual tonsillectomy.

\section{Conclusion}

Combined tongue base volume reduction and lingual tonsillectomy resulted in improvement of residual OSA symptoms and of PSG parameters in nonsyndromic children and in children with Down syndrome. Normalization of the PSG 
parameters after the surgery did not occur in the majority of the children who were obese or overweight. Combined tongue base volume reduction and lingual tonsillectomy can be considered in children with residual OSA after TA if there is posterior displacement of the tongue and hypertrophy of the lingual tonsils. A postoperative PSG should be obtained to evaluate possible residual OSA after tongue base reduction and lingual tonsillectomy. Further studies assessing larger patient groups, preferably from multiple centers, are warranted to better define the impact of demographics, comorbid conditions, BMI, the amount of reduction in the tongue volume, and the severity of OSA on the outcomes of combined tongue base volume reduction and lingual tonsillectomy.

\section{Conflicts of Interests}

The authors have no conflicts of interests to declare.

\section{References}

1 Ulualp SO, Szmuk P. Drug-induced sleep endoscopy for upper airway evaluation in children with obstructive sleep apnea. Laryngoscope 2013;123(01):292-297

2 Truong MT, Woo VG, Koltai PJ. Sleep endoscopy as a diagnostic tool in pediatric obstructive sleep apnea. Int J Pediatr Otorhinolaryngol 2012;76(05):722-727

3 Durr ML, Meyer AK, Kezirian EJ, Rosbe KW. Drug-induced sleep endoscopy in persistent pediatric sleep-disordered breathing after adenotonsillectomy. Arch Otolaryngol Head Neck Surg 2012;138(07):638-643

4 Wootten CT, Chinnadurai S, Goudy SL. Beyond adenotonsillectomy: outcomes of sleep endoscopy-directed treatments in pediatric obstructive sleep apnea. Int J Pediatr Otorhinolaryngol 2014; 78(07):1158-1162

5 Nakazawa K, Ikeda D, Ishikawa S, Makita K. A case of difficult airway due to lingual tonsillar hypertrophy in a patient with Down's syndrome. Anesth Analg 2003;97(03):704-705

6 Fricke BL, Donnelly LF, Shott SR, et al. Comparison of lingual tonsil size as depicted on MR imaging between children with obstructive sleep apnea despite previous tonsillectomy and adenoidectomy and normal controls. Pediatr Radiol 2006;36(06):518-523

7 Lin AC, Koltai PJ. Persistent pediatric obstructive sleep apnea and lingual tonsillectomy. Otolaryngol Head Neck Surg 2009;141(01): 81-85

8 Abdel-Aziz M, Ibrahim N, Ahmed A, El-Hamamsy M, Abdel-Khalik MI, El-Hoshy H. Lingual tonsils hypertrophy; a cause of obstructive sleep apnea in children after adenotonsillectomy: operative problems and management. Int J Pediatr Otorhinolaryngol 2011; 75(09):1127-1131

9 Prosser JD, Shott SR, Rodriguez O, Simakajornboon N, MeinzenDerr J, Ishman SL. Polysomnographic outcomes following lingual tonsillectomy for persistent obstructive sleep apnea in down syndrome. Laryngoscope 2017;127(02):520-524

10 Suh GD. Evaluation of open midline glossectomy in the multilevel surgical management of obstructive sleep apnea syndrome. Otolaryngol Head Neck Surg 2013;148(01):166-171

11 Propst EJ, Amin R, Talwar N, et al. Midline posterior glossectomy and lingual tonsillectomy in obese and nonobese children with down syndrome: Biomarkers for success. Laryngoscope 2017;127 (03):757-763

12 Friedman NR, Prager JD, Ruiz AG, Kezirian EJ. A Pediatric Grading Scale for Lingual Tonsil Hypertrophy. Otolaryngol Head Neck Surg 2016;154(01):171-174

13 Clark C, Ulualp SO. Multimodality assessment of upper airway obstruction in children with persistent obstructive sleep apnea after adenotonsillectomy. Laryngoscope 2017;127(05):1224-1230
14 Maturo SC, Mair EA. Submucosal minimally invasive lingual excision: an effective, novel surgery for pediatric tongue base reduction. Ann Otol Rhinol Laryngol 2006;115(08):624-630

15 Liu C, Ulualp SO. Outcomes of an alternating ibuprofen and acetaminophen regimen for pain relief after tonsillectomy in children. Ann Otol Rhinol Laryngol 2015;124(10):777-781

16 Berry R, Brooks R, Gamaldo C, et al. The AASM Manual for the Scoring of Sleep and Associated Events: Rules, Terminology and Technical Specifications. Version 2.0.2. Darien, IL: American Academy of Sleep Medicine; 2013

17 Tauman R, O'Brien LM, Ivanenko A, Gozal D. Obesity rather than severity of sleep-disordered breathing as the major determinant of insulin resistance and altered lipidemia in snoring children. Pediatrics 2005;116(01):e66-e73

18 Ulualp SO. Modified expansion sphincter pharyngoplasty for treatment of children with obstructive sleep apnea. JAMA Otolaryngol Head Neck Surg 2014;140(09):817-822

19 Imanguli M, Ulualp SO. Risk factors for residual obstructive sleep apnea after adenotonsillectomy in children. Laryngoscope 2016; 126(11):2624-2629

20 Mitchell RB, Kelly J. Outcome of adenotonsillectomy for obstructive sleep apnea in obese and normal-weight children. Otolaryngol Head Neck Surg 2007;137(01):43-48

21 Mitchell RB, Kelly J. Adenotonsillectomy for obstructive sleep apnea in obese children. Otolaryngol Head Neck Surg 2004;131 (01):104-108

22 Kang KT, Lee PL, Weng WC, Hsu WC. Body weight status and obstructive sleep apnea in children. Int J Obes 2012;36(07): 920-924

23 Hsu WC, Kang KT, Weng WC, Lee PL. Impacts of body weight after surgery for obstructive sleep apnea in children. Int J Obes 2013;37 (04):527-531

24 Kohler MJ, van den Heuvel CJ. Is there a clear link between overweight/obesity and sleep disordered breathing in children? Sleep Med Rev 2008;12(05):347-361, discussion 363-364

$25 \mathrm{Chu} \mathrm{L}, \mathrm{Li}$ Q. The evaluation of adenotonsillectomy on TNF- $\alpha$ and IL6 levels in obese children with obstructive sleep apnea. Int J Pediatr Otorhinolaryngol 2013;77(05):690-694

26 Tauman R, Gulliver TE, Krishna J, et al. Persistence of obstructive sleep apnea syndrome in children after adenotonsillectomy. J Pediatr 2006;149(06):803-808

27 Donnelly LF, Shott SR, LaRose CR, Chini BA, Amin RS. Causes of persistent obstructive sleep apnea despite previous tonsillectomy and adenoidectomy in children with down syndrome as depicted on static and dynamic cine MRI. AJR Am J Roentgenol 2004;183 (01):175-181

28 Shott SR, Donnelly LF. Cine magnetic resonance imaging: evaluation of persistent airway obstruction after tonsil and adenoidectomy in children with Down syndrome. Laryngoscope 2004;114 (10):1724-1729

29 Friedman NR, Parikh SR, Ishman SL, et al. The current state of pediatric drug-induced sleep endoscopy. Laryngoscope 2017;127 (01):266-272

30 Guilleminault C, Huseni S, Lo L. A frequent phenotype for paediatric sleep apnoea: short lingual frenulum. ERJ Open Res 2016;2 (03):00043-02016

31 Guilleminault C, Akhtar F. Pediatric sleep-disordered breathing: New evidence on its development. Sleep Med Rev 2015; 24:46-56

32 Huang YS, Guilleminault C. Pediatric Obstructive Sleep Apnea: Where Do We Stand? Adv Otorhinolaryngol 2017;80:136-144

33 Guilleminault C, Huang YS, Monteyrol PJ, Sato R, Quo S, Lin CH. Critical role of myofascial reeducation in pediatric sleep-disordered breathing. Sleep Med 2013;14(06):518-525

34 Chuang LC, Lian YC, Hervy-Auboiron M, Guilleminault C, Huang YS. Passive myofunctional therapy applied on children with obstructive sleep apnea: A 6-month follow-up. J Formos Med Assoc 2017;116(07):536-541 